\title{
Pharmacological priming of adipose-derived stem cells promotes myocardial repair
}

\author{
Jana S Burchfield, ${ }^{1}$ Ashley L Paul, ${ }^{1}$ Vishy Lanka, ${ }^{1}$ Wei Tan, ${ }^{1}$ Yongli Kong, ${ }^{1}$ \\ Camille McCallister, ${ }^{1}$ Beverly A Rothermel, ${ }^{1}$ Jay W Schneider, ${ }^{1}$ \\ Thomas G Gillette, ${ }^{1}$ Joseph A Hill ${ }^{1,2}$
}

\begin{abstract}
- Additional material is published online only. To view please visit the journa online (http://dx.doi.org/10. 1136/jim-2015-000018).

${ }^{1}$ Departments of Internal Medicine (Cardiology), University of Texas Southwestern Medical Center, Dallas, Texas, USA ${ }^{2}$ Department of Molecular Biology, University of Texas Southwestern Medical Center, Dallas, Texas, USA

\section{Correspondence to Dr Joseph A Hill, Division of Cardiology, University of Center, NB11.200, 6000 Dallas, TX 75390-8573, USA; joseph.hill@ utsouthwestern.edu} Texas Southwestern Medical Harry Hines Boulevard,
\end{abstract}

Accepted 18 November 2015

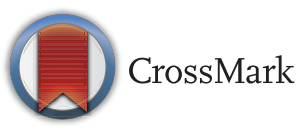

To cite: Burchfield JS, Paul AL, Lanka V, et al. $J$ Investig Med

2016;64:50-62.

\section{ABSTRACT}

Adipose-derived stem cells (ADSCS) have myocardial regeneration potential, and transplantation of these cells following myocardial infarction (MI) in animal models leads to modest improvements in cardiac function. We hypothesized that pharmacological priming of pre-transplanted ADSCs would further improve left ventricular functional recovery after MI. We previously identified a compound from a family of 3,5-disubstituted isoxazoles, ISX1, capable of activating an Nkx2-5-driven promoter construct. Here, using ADSCs, we found that ISX1 (20 mM, 4 days) triggered a robust, dose-dependent, fourfold increase in Nkx2-5 expression, an early marker of cardiac myocyte differentiation and increased ADSC viability in vitro. Co-culturing neonatal cardiomyocytes with ISX1-treated ADSCs increased early and late cardiac gene expression. Whereas ISX1 promoted ADSC differentiation toward a cardiogenic lineage, it did not elicit their complete differentiation or their differentiation into mature adipocytes, osteoblasts, or chondrocytes, suggesting that re-programming is cardiomyocyte specific. Cardiac transplantation of ADSCs improved left ventricular functional recovery following $\mathrm{Ml}$, a response which was significantly augmented by transplantation of ISX1- pretreated cells. Moreover, ISX1-treated and transplanted ADSCs engrafted and were detectable in the myocardium 3 weeks following $\mathrm{MI}$, albeit at relatively small numbers. ISX1 treatment increased histone acetyltransferase (HAT) activity in ADSCs, which was associated with histone 3 and histone 4 acetylation. Finally, hearts transplanted with ISX1-treated ADSCs manifested significant increases in neovascularization, which may account for the improved cardiac function. These findings suggest that a strategy of drugfacilitated initiation of myocyte differentiation enhances exogenously transplanted ADSC persistence in vivo, and consequent tissue neovascularization, to improve cardiac function.

\section{INTRODUCTION}

Globally, millions of people suffer from heart failure stemming from prior myocardial infarction (MI). This syndrome results from an inability to compensate for the loss of myocytes in the infarcted region. Currently, there are no pharmaceutical agents or medical devices that can directly mediate the regeneration of the

\section{Significance of this study}

What is already known on this subject?

- Currently, there are no pharmaceutical agents or medical devices that can directly mediate the regeneration of the heart muscle.

- Stem cell therapy has received much attention as a possible approach to mediate myocardial repair and thereby improve cardiac function. However, the efficacy of approaches involving delivery of exogenous cells to the injured myocardium is modest.

- Adipose tissue is a rich source of adult stem cells which can be isolated in large quantities by minimally invasive liposuction.

- Some evidence suggests that it is advantageous to foster differentiation of adult stem cells toward a cardiac lineage at the time of cell delivery to maximize reparative potential.

\section{What are the new findings?}

- We tested a strategy in which adipose-derived stem cells (ADSCs) are 'primed' by exposing them to ISX1, a small molecule previously established to promote stem cell differentiation toward a cardiomyocyte phenotype.

- We show that ISX1 treatment in culture promotes ADSC exit from the cell cycle and leads to expression of a variety of markers indicative of a cardiogenic lineage. Importantly, ISX suppressed differentiation into other cellular lineages.

- We observed that delivery of ISX1-primed ADSCs to an infarcted myocardium promoted rescue of the pathological remodeling phenotype above and beyond that afforded by vehicle-treated ADSCs. ISX1-treated ADSCS remained resident within the injured left ventricle for up to 3 weeks, and their administration was associated with enhanced angiogenesis.

- Together, these findings point to a novel strategy that capitalizes on synergies between pharmacological and cell-based modalities. 


\section{Significance of this study}

\section{How might it impact on clinical practice in the} foreseeable future?

- Current pharmacological therapies to treat cardiovascular diseases, such as ischemic heart disease, heart failure, peripheral vascular disease, do not reverse disease progression. Our study, using pharmacologically treated adipose-derived stem cells, may clinically prevent further tissue damage, enhance healing of damaged tissue, and provide adequate blood flow; thus, stopping or reversing disease progression.

- Few medications are available for the treatment of obesity, and most are FDA-approved for short-term use only. Obesity is a chronic disease, where there is an increase in fat cell (adipocyte) number. In our study, we identified a small molecule that can limit the differentiation of stem cells into mature, fat-containing adipocytes. Therefore, in the future, this molecule may be used to prevent adipogenesis, independent of dietary intake.

heart muscle. ${ }^{12}$ Stem cell therapy has received much attention as a possible approach to mediate myocardial repair and thereby improve cardiac function. Unfortunately, the efficacy of approaches involving the delivery of exogenous cells to the injured myocardium is modest. Furthermore, compared with the number of myocytes lost in an MI, only a small number of cells can be administered and only a tiny fraction of those persist within the tissue.

Most clinical trials of myocardial regeneration have employed adult bone marrow stem cells. ${ }^{3}{ }^{4}$ However, adipose tissue is an even richer source of adult stem cells. Adipose-derived stem cells (ADSCs) can be isolated in large quantities by minimally invasive liposuction producing a higher yield of stem cells per volume. ${ }^{5}$ Cells derived from this tissue include mesenchymal stem cells, endothelial progenitor cells, pericytes, and adipose progenitor cells. Transplantation of these cells can improve cardiac function in animal models. ${ }^{6-13}$ However, cardiogenic conversion in vivo is rare.

In the great majority of studies, exogenous cells delivered to the injured myocardium do not differentiate into significant numbers of cardiomyocytes, nor do they persist in the tissue beyond a few days. Rather, their passage through the tissue appears to trigger a response which is poorly characterized, but which may involve neovascularization, re-entry of some cell types into the cell cycle, or other events. In any case, effect sizes observed to date remain modest.

Some evidence suggests that it is advantageous to foster differentiation of adult stem cells toward a cardiac lineage at the time of cell delivery to maximize reparative potential. This strategy has been accomplished by transfecting cells with small interfering RNA (siRNA) or expression constructs $^{14-16}$ or by co-transplantation with cells engineered to express proteins capable of directing stem cell differentiation. ${ }^{17-21}$ Another strategy entails use of small molecules or proteins to promote cardiogenic conversion. ${ }^{22}$
We previously screened a large chemical library and identified small molecules capable of activating the transcription factor, Nkx2.5, one of the earliest lineage-restricted genes to be expressed in cardiac progenitor cells. ${ }^{23}$ This screen was engineered using a firefly luciferase (luc) gene inserted into the $N k x 2.5$ locus on a $180-\mathrm{kb}$ mouse bacterial artificial chromosome harboring all of the transcriptional and epigenetic regulatory elements necessary for the cardiac-specific expression of $N k x 2.5$. This gene was then stably integrated into P19 carcinoma cells (subclone CL6; P19CL6) for high throughput screening. ${ }^{22}{ }^{24}$ Small molecules identified in this screen offer significant advantages over previous screens for cardiogenic small molecules that targeted late cardiac differentiation markers such as $\alpha$-myosin heavy chain $(\alpha-M H C)$ or atrial natriuretic factor (ANF). ${ }^{25} 26$ Transplantation of human peripheral blood mononuclear cells treated with the compounds we isolated in our Nkx2.5 screen improved cell engraftment and functional recovery in cryoinjured rat hearts. ${ }^{22}$ In addition, these molecules activated muscle-specific transcriptional programs in multipotent Notch-activated epicardiumderived cells (NECs), ${ }^{27}$ directed neuronal cell fate determination, ${ }^{24} 28$ induced myofibroblast differentiation, ${ }^{29}$ and increased insulin production in pancreatic $\beta$ cells. ${ }^{30}$ We set out to test whether one of the most promising of these small molecules, a 3,5-disubstituted isoxazole (ISX1), could direct ADSCs into a cardiac lineage and foster myocardial repair.

\section{METHODS}

\section{ADSC isolation and gene expression analysis}

The mice from which ADSC isolation was performed were euthanized with a lethal dose $(120 \mathrm{mg} / \mathrm{kg})$ of sodium pentobarbital. White adipose tissue from posterior subcutaneous (inguinal), perigonadal, visceral retroperitoneal, anterior subcutaneous (interscapular) of $\mathrm{C} 57 \mathrm{BL} 6 / \mathrm{J}$ or ubiquitin- green fluorescent protein (GFP) transgenic (GFP expressed from the ubiquitin $\mathrm{C}$ promoter) mice (The Jackson Laboratory, Bar Harbor, Maine, USA) was digested in adipose isolation buffer (100 mM HEPES, $120 \mathrm{mM}$ $\mathrm{NaCl}, 50 \mathrm{mM} \mathrm{KCl}, 1 \mathrm{mM} \mathrm{CaCl}{ }^{2}$, pH 7.4) with collagenase I for $1 \mathrm{~h} 40 \mathrm{~min}$ at $37^{\circ} \mathrm{C}$ with shaking at $100 \mathrm{RPM}$. Digested adipose was filtered through a $210 \mu \mathrm{m}$ filter, and mature adipocytes were discarded. Red blood cells within the stromal vascular fraction (SVF) were lysed using ammonium chloride, and the SVF was filtered through a $30 \mu \mathrm{m}$ filter, washed in $1 \times$ phosphate-buffered saline (PBS), and plated at $80,000 \mathrm{cells} / \mathrm{cm}^{2}$. After $24 \mathrm{~h}$, the cell culture medium was changed, and cells were exposed, at preconfluency, to various concentrations of ISX1 $(0.2,2,20$, $80 \mu \mathrm{M})(\mathrm{n}=4)$, or subsequently at $20 \mu \mathrm{M}$ ISX1 or vehicle (Dimethyl sulfoxide [DMSO]) for variable lengths of time $(1,4,7$ days) $(n=3-7)$. The empirically determined effective dose of $20 \mu \mathrm{M}$ ISX1 and exposure time of 4 days were used in all experiments.

Isolated RNA was reverse transcribed with subsequent quantitative real-time PCR analysis using TaqMan Nkx2-5 specific primers $(n=4)$. ADSCs were co-cultured with neonatal rat cardiomyocytes (NRVMs, 1:10), treated with diluent or $20 \mu \mathrm{M}$ ISX1, and RNA was isolated after 3 weeks of co-culturing $(n=4-7)$. Mouse gene expression was measured using quantitative real-time PCR and 
TaqMan mouse-specific primers: Troponin C, Atrial natriuretic factor (Anf), Brain natriuretic peptide (Bnp).

\section{Primary culture of NRVMs}

Neonatal rat pups were separated from the dam on the morning immediately following parturition. They were placed in a $1500 \mathrm{~mm}$ Petri dish chilled to $4^{\circ} \mathrm{C}$ and resting on crushed ice. Following a 10 min period of low temperature acclimation, the pups were euthanized by decapitation and their hearts harvested for further processing.

Cardiomyocytes were isolated and plated as previously described. ${ }^{31}$ Briefly, left ventricles of Sprague-Dawley rats aged 1-2 days were collected and digested with collagenase. The resulting suspension was pre-plated to remove fibroblasts. Myocytes were plated at a density of 1250 cells/ $\mathrm{mm}^{2}$ in cell culture medium containing $10 \%$ fetal calf serum and $100 \mu \mathrm{mol} / \mathrm{L}$ of bromodeoxyuridine. Cells were 95\% pure cardiomyocytes, which were co-cultured with ADSCs at a ratio of 10:1.

\section{Immunocytochemistry for $\mathbf{N k x 2 - 5}$ in cells}

After 4 days with ISX1 or DMSO, ADSCs were washed with PBS, fixed with $4 \%$ paraformaldehyde for $30 \mathrm{~min}$, and incubated for $3 \mathrm{~h}$ at $30^{\circ} \mathrm{C}$ with a mixture of $\mathrm{MeOH}$ : DMSO (4:1). Immunocytochemistry was performed using rabbit anti-Nkx2-5, IgG antibody (1:200) (Gene Tex) overnight with subsequent secondary antibody incubation for 30 min (goat anti-rabbit Cy3 1:200), and counterstaining was performed using $2 \mu \mathrm{g} / \mathrm{mL}$ Hoechst 33342 dye (Molecular Probes).

\section{Flow cytometry}

Cells were incubated with antibodies for markers of mesenchymal stem cells (CD105, CD44, CD90.1, CD73, CD166), adipose progenitor cells (CD29, CD34, Sca1, CD24), endothelial cells (CD31), hematopoietic stem cells (CD45, CD117), and monocytes (CD11b, CD14) along with their respective isotype control antibodies (eBiosciences, San Diego, CA) listed in online supplementary methods. Cells were analyzed using FACS Caliber (BD) $(n=2)$.

\section{Cell viability and cell proliferation}

ADSC viability was measured using the CellTiterBlue Assay (viable cells reduce resazurin into fluorescent resorufin) $(n=2)$. Briefly, 25,700 cells were plated on a 96-well plate, ISX1 or DMSO was added for 4 days, and CellTiterBlue was added for $4 \mathrm{~h}$ at $37^{\circ} \mathrm{C}$. ADSC proliferation was measured using a colorimetric Cell Proliferation ELISA, BrdU (Roche). For analysis of BrdU incorporation, cells were plated at a density of 12,750 cells/well on a 96 well plate, ISX1 or DMSO was added for 4 days, and cells were exposed to the BrdU antibody $(n=2)$.

\section{$\mathrm{MI}$ and cell transplantation}

Mice were anesthetized by intraperitoneal injection of ketamine/midazolam $(100 \mathrm{mg} / \mathrm{kg}$ and $1 \mathrm{mg} / \mathrm{kg}$, respectively) and maintained under inhalation of $1.5 \%$ isoflurane during the surgical procedure. Left anterior descending (LAD) coronary artery ligation of female C57BL6/J mice aged 912 weeks (The Jackson Laboratory) was performed as previously described. ${ }^{32}$ ADSCs from male ubiquitin-GFP mice were treated for 4 days with DMSO or $20 \mu \mathrm{M}$ ISX1 and $0.3 \times 10^{6}$ to $0.4 \times 10^{6}$ cells in $50 \mu \mathrm{L}$ by intramyocardial injection into the peri-infarct region of female C57BL6/J mice immediately after LAD ligation (5 injection sites) in a blinded manner. Sham-operated mice were subjected to thoracotomy, suturing around the LAD without occlusion, followed by surgical closure. No cells were transplanted into sham-operated control hearts.

\section{Echocardiography}

Cardiac function was measured using high-resolution two-dimensional targeted M-mode echocardiography on anesthetized mice (Vevo 2100 small-animal microultrasound system, VisualSonics, Toronto, Canada) $(n=10-15)$. Data were analyzed in a blinded manner.

\section{Measurement of infarct size}

In a separate series of mice, infarct sizes at 1 day after MI were measured. Mice were subjected to MI in which the LAD coronary artery is surgically ligated. Animals were maintained on $0.8 \%$ isoflurane as anesthesia throughout the surgical procedure. Toe pinch was employed at random intervals to ensure that an adequate plane was maintained. Immediately postoperative and prior to regaining consciousness, the mice were treated with $0.5 \mathrm{mg} / \mathrm{kg}$ Buprenorphine Lab SR and monitored for signs of pain or distress twice daily for $72 \mathrm{~h}$ and daily thereafter.

Five to six $1 \mathrm{~mm}$ sections of 1-day post-MI hearts were incubated for $20 \mathrm{~min}$ at $37^{\circ} \mathrm{C}$ with $1 \% 2,3,5$-tripheyltetrazolium chloride (TTC), and percent infarct was calculated by measuring the area of infarct and weight of each section. The weight of the infarction $=(\mathrm{A} 1 \times \mathrm{W} 1)+(\mathrm{A} 2 \times \mathrm{W} 2)+(\mathrm{A} 3 \times \mathrm{W} 3)$ $+(\mathrm{A} 4 \times \mathrm{W} 4)+(\mathrm{A} 5 \times \mathrm{W} 5)$ and percent infarct $=($ weight of the infarction/weight of left ventricle (LV)) $\times 100(n=5-6)$.

\section{Immunohistochemistry}

Transplanted ubiquitin-GFP cells were detected in frozen sections of 3-week post-MI hearts using rabbit anti-GFP antibody (1:200) (Invitrogen) and goat Cy3-anti-rabbit (1:200). In addition, tissue sections from the heart, kidney, lung, skeletal muscle, spleen, liver, and white adipose tissue were assessed using rabbit anti-GFP antibody (1:200) (Invitrogen) and streptavidin HRP (1:800) with TACS Blue Label (R\&D Systems). Photographs were taken at $400 \times$ and $630 \times$ magnification. The presence of transplanted cells was verified using confocal microscopy. Frozen sections of hearts 3 weeks post-MI and 3 weeks post-cell transplant were stained with Fluorescein isothiocyanate (FITC) conjugated BS-I Isolectin B4 from Bandeiraea simplicifolia (Sigma, St. Louis, Missouri, USA) at a 1:75 dilution for vascular membrane staining. Fifteen photos in the border zones of each heart at $200 \times$ magnification were quantified for vessel density and calculated as number of vessels/field $(n=7-11)$.

\section{ADSC differentiation}

ADSCs were grown in an Methylisobutylxanthine, Dexamethasone, Insulin (MDI) induction medium $(1 \times$ Dulbecco's Modified Eagle Medium (DMEM), 10\% Fetal Bovine Serum (FBS), $0.5 \mathrm{mM}$ 3-isobutyl1-methyxanthine, $160 \mathrm{nM}$ insulin, $250 \mathrm{nM}$ dexamethasone (Sigma)) for 2 days, then in an insulin-containing medium 
(160 $\mathrm{nM}$ insulin) for 2 days followed by culturing in $1 \times \mathrm{DMEM}$ for 3 weeks. Mature adipocytes were stained with $0.12 \%$ Oil Red O, and photographs were taken at $\times 400$ magnification. Oil Red O stain was eluted using 100\% isopropanol and measured at $500 \mathrm{~nm}(\mathrm{n}=3)$. ADSCs were differentiated into osteoblasts for 3 weeks using osteogenic differentiation medium: $1 \times$ DMEM, 10\% FBS, $0.1 \mu \mathrm{M}$ dexamethasone, $50 \mu \mathrm{M}$ 2-phosho-L-ascorbic acid trisodium salt, $10 \mathrm{mM}$ glycerol-2-phosphate disodium salt hydrate. Cells were stained with $2 \%$ alizarin red for $45 \mathrm{~min}$, photos were taken at $\times 200$ magnification, and the stain was eluted with $10 \%$ cetylpyridinium and measured at $540 \mathrm{~nm}(\mathrm{n}=4)$. Von Kossa staining was performed using 5\% silver nitrate for $30 \mathrm{~min}$ in the dark with subsequent exposure to ultraviolet light for $1 \mathrm{~h}$, with photos taken at $200 \times$ magnification. For chondrogenic differentiation, ADSCs were pelleted in a $15 \mathrm{~mL}$ tube and differentiated into chondrocytes using $1 \times$ DMEM, $1 \%$ FBS, $10 \mathrm{ng} / \mathrm{mL}$ TGF $\beta 1,155 \mu \mathrm{M} 2-$ phosho-L-ascorbic acid trisodium salt, $1 \%$ solution of insulin, transferrin, selenium, and $0.1 \mu \mathrm{M}$ dexamethasone. At the end of 3 weeks, pellets were digested with papain and sulfated glycosaminoglycans were measured using dimethylmethylene blue reagent at $525 \mathrm{~nm}$. Data were quantified on the basis of a standard curve using whale chondroitin 4-sulfate $(n=4)$.

\section{Histone acetyltransferase and deacetylase activity}

Histones were isolated using the EpiQuik Total Histone Extraction Kit according to the manufacturer's instructions with the exception of no addition of dithiothreitol (Epigentek). Histone acetyltransferase (HAT) and histone deacetylase (HDAC) activities were measured in nuclear extracts of ADSCs exposed to $20 \mu \mathrm{M}$ ISX1 or DMSO for 4 days using a colorimetric assay $(440 \mathrm{~nm})$ according to the manufacturer's instructions (BioVision) $(n=4$ and 3 , respectively). Positive controls included HeLa cell nuclear extracts and HDAC inhibition using $5 \mu \mathrm{M}$ trichostatin A (TSA, Sigma). HDAC inhibitors, valproic acid (Sigma) and TSA, were added daily with a fresh medium containing either DMSO or ISX1. Treated cells were subsequently analyzed for $N k x 2-5$ gene expression $(n=4-8$ and $n=5-7$, respectively).

\section{Western blotting}

Histones were isolated using the EpiQuik Total Histone Extraction kit (Epigentek) according to the manufacturer's instructions. Lysates $(2.5 \mu \mathrm{g})$ were separated using $12.5 \%$ sodium dodecyl sulfate polyacrylamide gel electrophoresis (SDS-PAGE) and transferred to the Polyvinylidene difluoride (PDVF) membrane. Membranes were incubated with acetylated histone $\mathrm{H} 3 \mathrm{~K} 9$ polyclonal, acetylated histone H4K8 polyclonal antibodies (Epigenetek), histone 3, trimethylated histone $\mathrm{H} 3 \mathrm{~K} 9$, trimethylated histone $\mathrm{H} 3 \mathrm{~K} 4$ polyclonal antibodies (Abcam), and histone 4 antibody (Santa Cruz). Band densities on the western blots were quantified using Image $\mathrm{J}$ software $(n=3)$.

\section{Protein array}

Paracrine factors released into cell culture media were measured using a RayBio Mouse Angiogenesis Array according to the manufacturer's instructions (RayBiotech, Inc). Individual dot intensities were quantified by densitometry and internal positive controls were used to normalize between different membranes $(n=2)$.

\section{Approvals}

The study was approved by the UT Southwestern Institutional Animal Care and Use Committee, and all animal procedures conform to NIH guidelines (Guide for the Care and Use of Laboratory Animals).
Figure 1 Adipose-derived stem cells (ADSCs) express Nkx2-5 in response to ISX1. (A) Increased Nkx2-5 gene expression in ADSCs treated for 4 days with ISX1 compared with vehicle (DMSO). Data include $n=4-5$ in each group and are presented as mean \pm SEM, ${ }^{*} p<0.05$. (B) Immunocytochemistry of nuclear $\mathrm{Nkx2-5}$ protein in vehicle-treated and ISX1-treated ADSCs. Nkx2.5 (red) and Hoechst 33342 dye (blue). Bar $=40 \mu \mathrm{m}$.
A

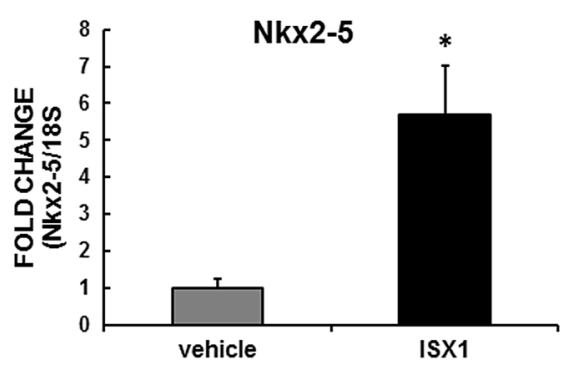

B

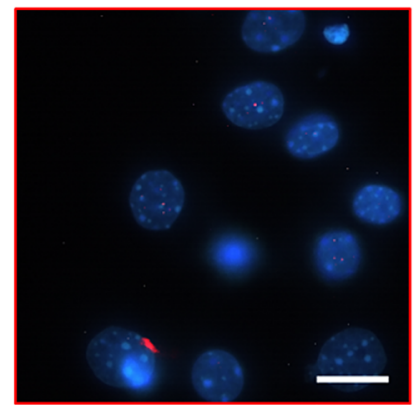

vehicle

ISX1

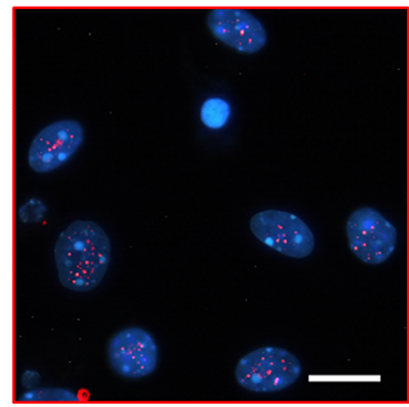

Nkx2.5 (red)/Hoechst 33342 dye (blue) 

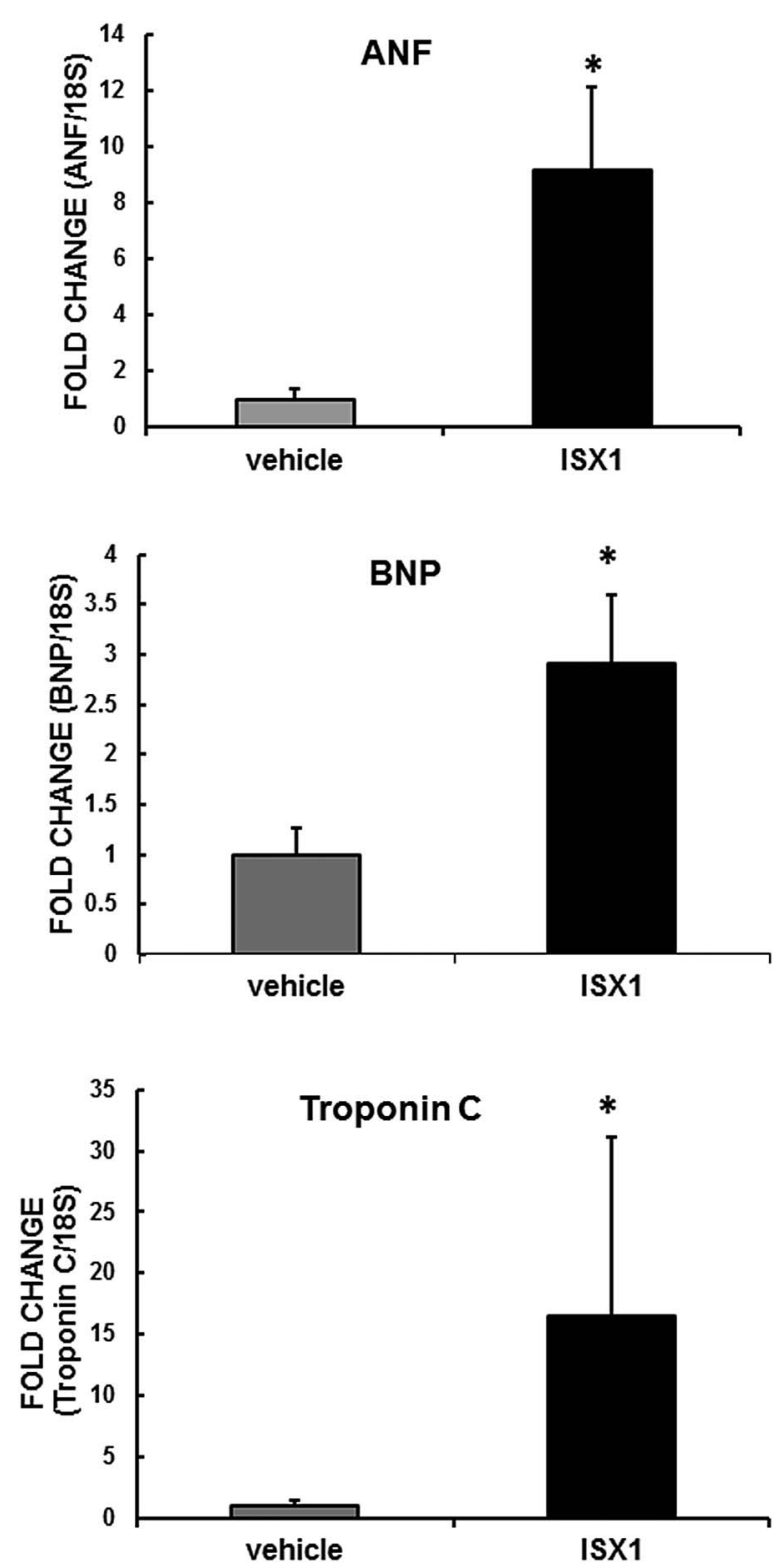

Figure 2 ISX1 augments cardiac gene expression in adipose-derived stem cells (ADSCs) co-cultured with neonatal cardiomyocytes (NRVMs). Increased cardiac gene expression (ANF, BNP, Troponin C) in cells co-cultured with NRVMs for 3 weeks and exposed to ISX1 compared with vehicle (DMSO). Data include $\mathrm{n}=4-7$ in each group and are presented as mean \pm SEM, * $p<0.05$

\section{Statistical analysis}

Statistical analyses were performed using StatView software. Error bars in graphs of three or more independent cell isolations indicate $\pm S E$ of the mean (SEM). Error bars in graphs of two independent cell isolations indicate $\pm S D$. Comparisons between two groups of three or more independent isolations were performed using a two-tailed unpaired Student's t test (figures 1-3, 4A,D and 5B,D). Comparisons between three or more groups were performed using one-way analysis of variance, followed by the Student-Neumann-Keuls post hoc test (figures 4B,C, 6B-D and 7C).

\section{RESULTS}

Characterization of ADSCs

Cells from the SVF of mouse white adipose tissue and SVF maintained in culture for 4 days, denoted as passage 0 (P0), were characterized by flow cytometry. Flow cytometry data are shown from one representative experiment for P0 and SVF (see online supplementary figure S1A,B, respectively) and quantitated data isolations are shown in online supplementary figure S2. The SVF and the P0 cells expressed markers of adipose progenitors (CD29, CD34, Sca1, CD24) and mesenchymal stem cell markers (CD105, CD73) (table 1). Inflammatory cells were detected in the SVF and not the P0 cells, which was the passage used for all subsequent experiments. Importantly, we noted the presence of CD34, a marker which distinguishes activated early progenitors from quiescent cells ${ }^{33}$ and indicates increased differentiation potential. ${ }^{34} \mathrm{CD} 34$ levels decline with longterm maintenance in culture. ${ }^{35}$ Therefore, subsequent experiments were performed using cells with limited time and passaging in culture.

\section{Pharmacological priming of ADSCs}

Treatment of ADSCs with $20 \mu \mathrm{M}$ ISX1 resulted in a robust increase in Nkx2-5 gene expression as measured by qPCR (figure 1A). Data were derived from four to five different cell isolations in each group, performed in triplicate per experiment. This increase was both dose $(n=4$ at each concentration of ISX1) and time dependent $(n=3-7)$ (see online supplementary figure S3A,B). ISX1-elicited increases in $\mathrm{Nkx} 2.5$ protein levels, which was observed by immunostaining (figure 1B). ISX1 was not toxic to ADSCs at any concentration for up to 4 days (see online supplementary material 4A). However, long-term treatment (3 weeks) with a dose of $80 \mu \mathrm{M}$ caused cell death as assessed by visualization of hematoxylin-stained cells (see online supplementary figure $4 B)(n=2)$. It is well known that on differentiation, stem cells exit the cell cycle and cease to divide. Consistent with ISX1 promoting differentiation of ADSCs, there was a dose-dependent decrease in cell proliferation (see online supplementary figure 4C) $(n=2)$.

To examine the ability of ISX1 to promote differentiation toward a cardiomyocyte-like phenotype, we co-cultured mouse ADSCs with NRVMs (1:10) and measured early and late cardiac marker gene expression, including ANF, brain natriuretic peptide (BNP), and troponin C by qPCR using mouse-specific primers. ISX1-treated cultures manifested significant increases in all three of these markers as compared with vehicle-treated controls (figure 2) $(n=4-7)$. These data suggest that ISX1-treated ADSCs adopt a phenotype mimicking that of cardiac myocytes.

\section{Inhibition of other ADSC differentiation pathways}

Since ADSCs have the capacity to differentiate into a variety of tissues of mesenchymal origin, including adipose tissue, bone, and cartilage, we determined whether ISX1 promoted ADSCs differentiation into adipocytes, osteoblasts, and chondrocytes. To examine adipocyte differentiation, we cultured ADSCs for 21 days using adipogenic differentiation medium in the presence or absence of ISX1. Using Oil Red $\mathrm{O}$ staining as a marker of adipocyte differentiation, we found that ISX1 suppressed adipogenesis as compared with 
Figure 3 Adipose-derived stem cells (ADSCs) manifest diminished capacity to undergo adipogenesis, osteogenesis, and chondrogenesis in response to ISX1. (A) Representative images of Oil Red 0 staining in ADSCs differentiated (3 weeks) into mature adipocytes and treated with vehicle (DMSO) or ISX1. Bar $=20 \mu \mathrm{m}$. Black arrows indicate Oil Red 0 lipid droplets. (B) Quantification of eluted Oil Red 0 stain. (C) Representative images of Alizarin Red staining in ADSCs differentiated ( 3 weeks) into mature osteoblasts and treated with vehicle (DMSO) or ISX1. Bar $=40 \mu \mathrm{m}$. (D) Quantification of eluted Alizarin Red stain. (E) Representative images of von Kossa staining in ADSCs differentiated ( 3 weeks) into mature osteoblasts and treated with vehicle (DMSO) or ISX1. Bar $=40 \mu \mathrm{m}$. (F) Quantification of sulfated glyosaminoglycans after 3 weeks in chondrogenesis differentiation medium and exposed to vehicle (DMSO) or ISX1. Data include $\mathrm{n}=3-4$ per group and are presented as mean \pm SEM $\left({ }^{*} p<0.05\right)$.
A

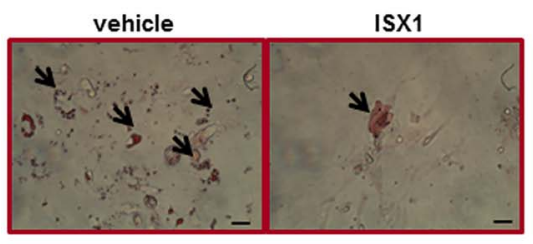

B
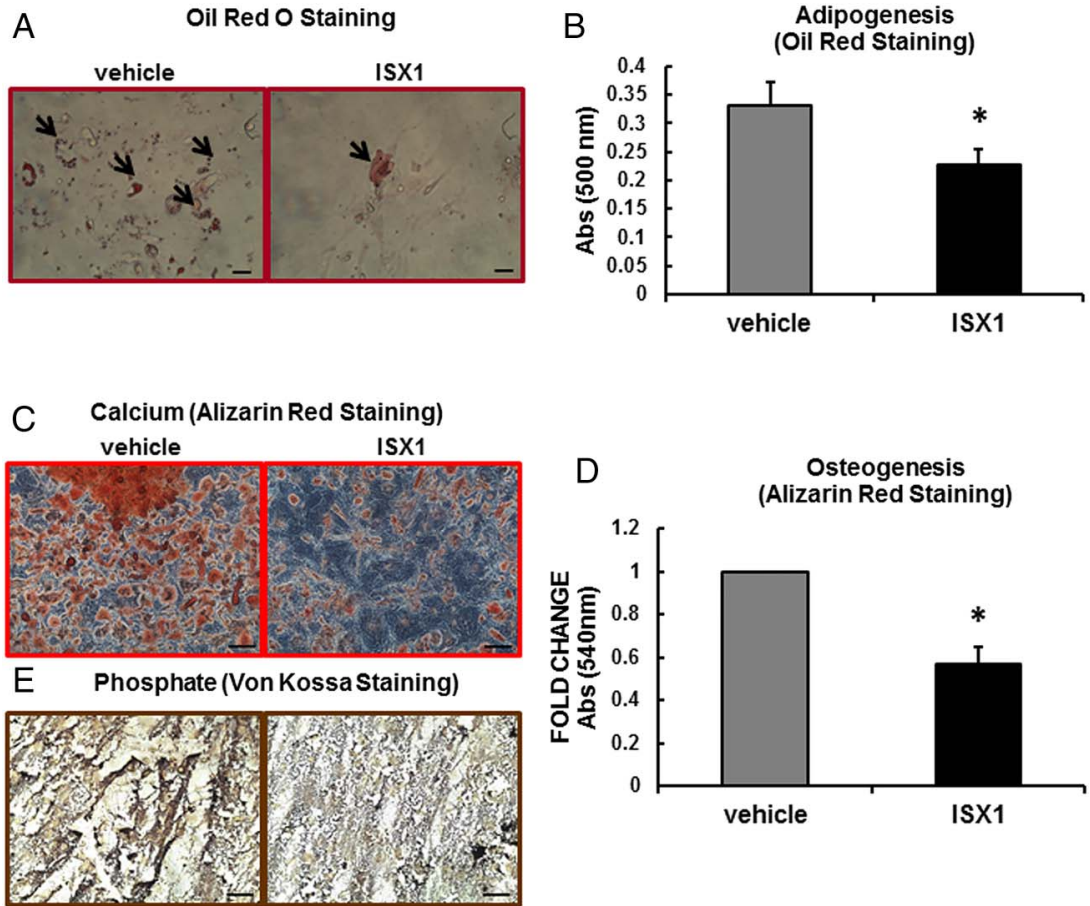

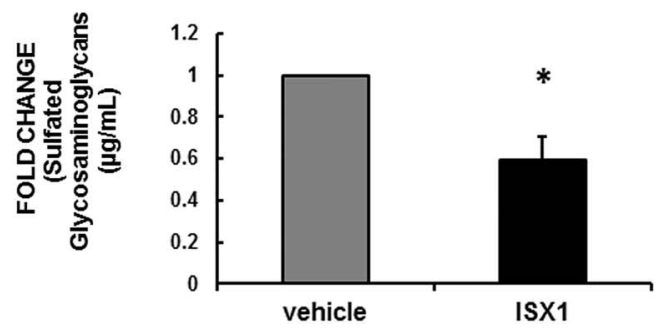

$\mathrm{F}$

Chondrogenesis

ISX1

vehicle-treated controls (figure 3A), a finding which is not due to a decrease in cell number as visualized by hematoxylin staining (see online supplementary figure 3C). Lipid accumulation was quantified by eluting intracellular Oil Red $\mathrm{O}$ stain using isopropanol and measuring amounts by spectrophotometry (figure $3 \mathrm{~A}, \mathrm{~B})(\mathrm{n}=3)$.

To determine whether ISX1 provoked osteogenic differentiation, we exposed ISX1-treated and vehicle-treated ADSCs to an osteogenic medium for 21 days. ISX1 led to a decrease in the osteogenic capacity of ADSCs as shown by Alizarin Red and von Kossa staining (figure 3C-E) $(n=4)$. We also measured sulfated glycosaminoglycans after 21 days of exposure to a chondrogenic differentiation protocol and found that ISX1 inhibited ADSC differentiation into chondrocytes (figure $3 \mathrm{~F})(\mathrm{n}=4)$. In aggregate, these results suggest that ISX1 can specify the differentiation pathway of ADSCs, limiting differentiation into adipose, bone, or cartilage lineages while promoting differentiation toward a cardiac lineage.

\section{ISX1-elicited chromatin remodeling}

Stem cell differentiation involves a tightly regulated program of gene expression governed by both genetic and epigenetic mechanisms. Histone acetylation states (regulated by HATs and HDACs) are a major determinant of stem cell differentiation. ${ }^{36}$ To test for a role of epigenetic mechanisms in ADSC-dependent ISX1-primed myocardial repair, we first evaluated HDAC activity, observing that ISX1 did not change HDAC activity in ADSCs (figure 4A) $(\mathrm{n}=3)$. Further, the effects of ISX1 on Nkx2-5 expression could not be mimicked by the HDAC inhibitors valproic acid (VPA) $(n=4-8)$ or TSA $(n=5-7)$ (figure 4B,C). However, ISX1 did provoke an increase in HAT activity $(n=4)$, culminating in an increase in the acetylation of histones 3 and 4, key molecules involved in cell differentiation $(n=3)^{3738}$ (figures 4D and 5A-D).

Acetylation of specific lysine residues on histones 3 and 4 help determine whether a gene is transcriptionally active versus repressed. ${ }^{39}$ Pertinent to this, we found that ISX1 provoked an increase in the acetylation of lysine 9 (histone 3 ) and lysine 8 (histone 4) (figure 5A-D). ISX1 treatment did not lead to a decrease in trimethylated histone 3 lysine 9, a 'repressive mark', ${ }^{40}$ or to an increase in the 'active mark', trimethylated histone 3 lysine $4^{41 \quad 42}$ (see online supplementary figure 5). These results suggest that ISX1-elicited alterations in gene expression involve changes in histone acetylation via an increase in HAT activity rather than changes in histone methylation. 
Figure 4 ISX1 increased histone acetyltransferase (HAT) activity but not histone deacetylase (HDAC) activity in adipose-derived stem cells (ADSCs), and HDAC inhibition alone is insufficient to induce $N k x 2-5$ gene expression. (A) HAT activity of nuclear extracts of ADSCs treated with ISX1 or vehicle (DMSO). Data include $n=4$ per group and are presented as mean \pm SEM $(p<0.05)$. (B) HDAC activity in nuclear extracts of ADSCs treated with ISX1 or vehicle (DMSO). Data include $\mathrm{n}=3$ per group (NS, non-significant). (C) $N k x 2.5$ gene expression after addition of valproic acid (VPA) alone or in combination with ISX1. Data include $n=4-8$ in each group. (D) Nkx2.5 gene expression after addition of trichostatin A (TSA) alone or in combination with ISX1. Data include $n=5-7$ in each group.
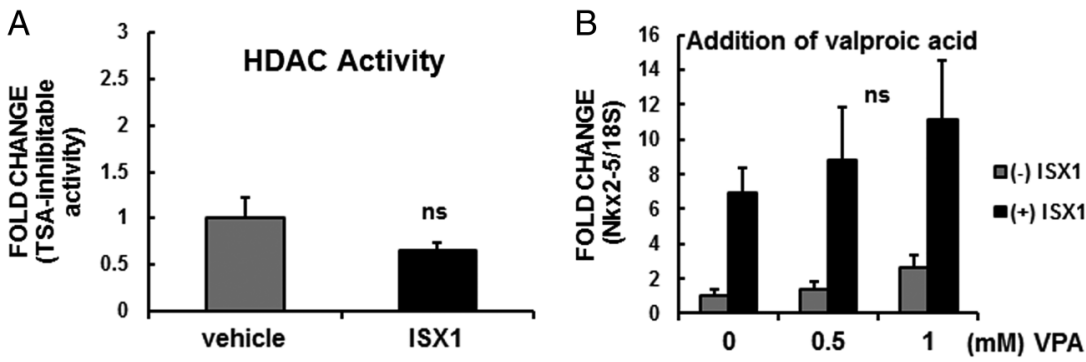

C

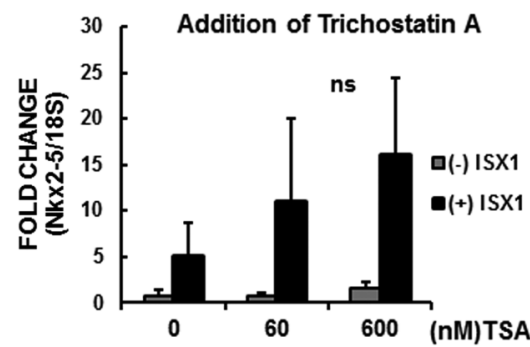

\section{Transplantation of ISX1-primed ADSCs after MI}

A number of studies have demonstrated efficacy of exogenously derived stem cells in promoting myocardial regeneration in the setting of $\mathrm{MI}^{3}{ }^{43}$ Our results suggest that ISX1-treated ADSCs may be 'primed' toward a cardiomyocyte fate, which we hypothesize facilitates paracrine signaling events that promote repair. To test this, we studied a mouse model of MI in which the LAD coronary artery is surgically ligated and ADSCs treated with either vehicle or ISX1 are transplanted into the myocardium at the time of surgery. Sham-operated and mock-transplanted MI-injured animals served as controls. Representative echocardiograms are shown in figure 6A. Transplantation of ADSCs $\left(0.3 \times 10^{6}\right.$ to $0.4 \times 10^{6}$ cells $)$ immediately following MI led to an improvement in contractile performance $(\mathrm{p}<0.05)$ measured by echocardiography and quantified as percent fractional shortening (\%FS) 3 weeks post-MI (21.1 $1.4 \%)$ as compared with mock-transplanted hearts $(15.9 \pm 1.7 \%)$ $(n=10-15)$ (figure 6B). Treatment of ADSCs with ISX1 for 4 days prior to transplantation did not lead to significant changes in left ventricular diastolic dimension (figure 6C). Treatment of ADSCs with ISX1 for 4 days prior to transplantation was associated with yet further protection of systolic function $(27.1 \pm 1.1 \% \mathrm{FS})$, as well as a decrease in left ventricular end systolic dimension (LVESD) (figure 6D).

To ensure that these differences in cardiac function were not a consequence of differences in initial infarct size, we performed 2,3,5-triphenyltetrazolium chloride (TTC) staining $24 \mathrm{~h}$ after ligation of the LAD coronary artery in a separate series of mice. There were no statistically significant differences in infarct size between hearts transplanted with cells or those injected with the diluent of cells or between vehicle-treated cells and ISX1-treated cells at day 1 (figure $7 \mathrm{~A})(\mathrm{n}=5-6)$ or scar size (see online supplementary
Figure 5 ISX1 increased histone 3 and 4 acetylation and histone 4 lysine 8 acetylation. (A) Representative western blot illustrating increased acetylation of histone 3 lysine 9 (H3K9) in response to ISX1. (B) Quantification of acetylated H3K9 compared with total histone 3. Data include $n=3$ in each group. Data are presented as mean \pm SEM ( $\left.{ }^{*} p<0.05\right)$. (C) Representative western blot illustrating increased acetylation of histone 4 lysine 8 (H4K8) in response to ISX1. (D) Quantification of acetylated H4K8 compared to total histone 4. Data include $n=3$ per group.
A

Western Blotting

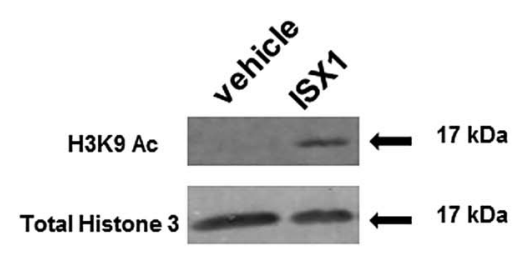

B H3K9 Acetylation

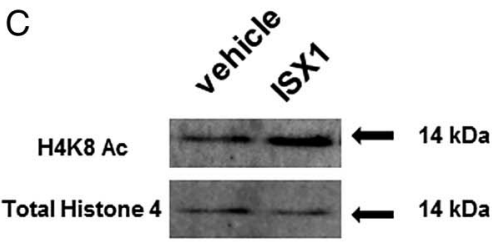

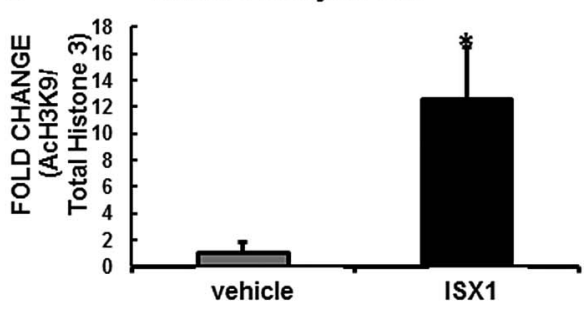

D

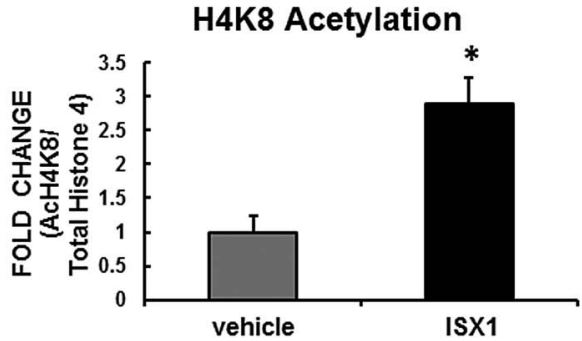


A

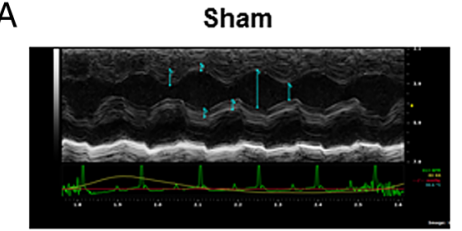

MI with diluent of cells

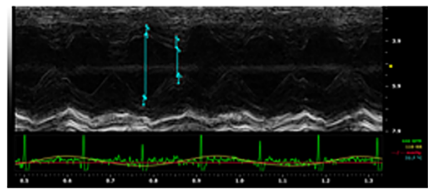

MI with vehicle-tx cells

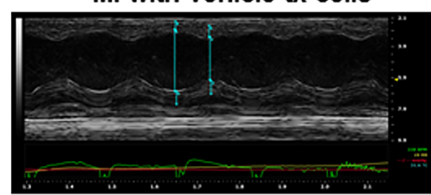

MI with ISX1-tx cells

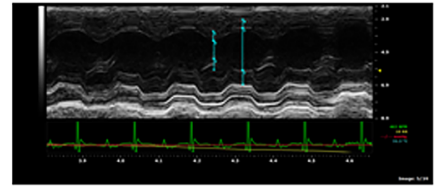

D
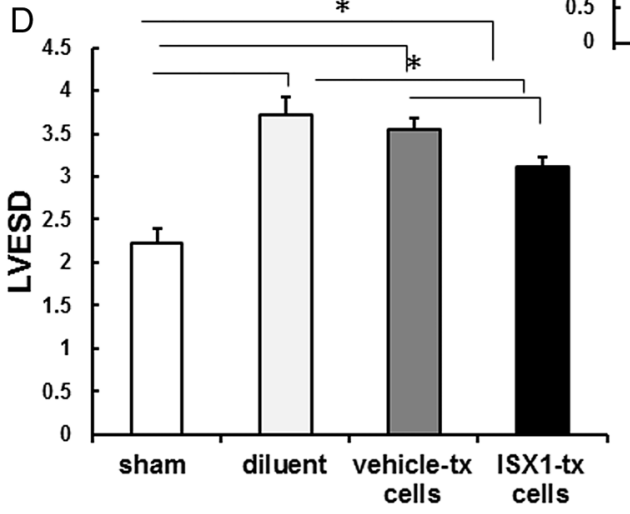

B

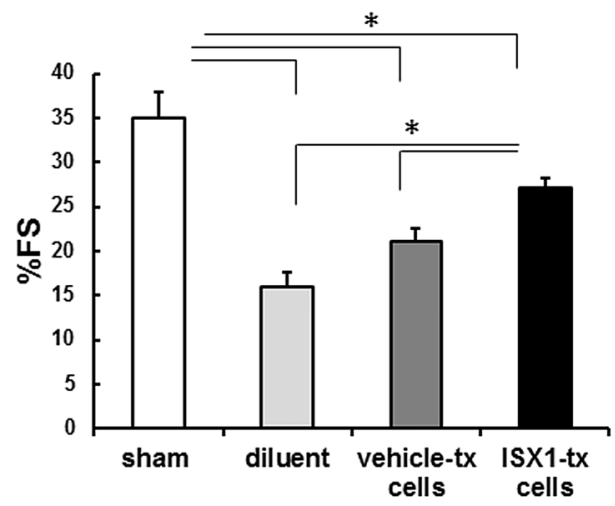

C

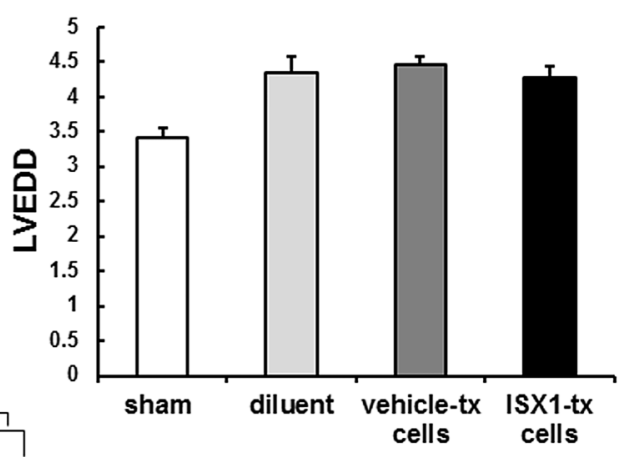

Figure 6 Transplantation of adipose-derived stem cells (ADSCs) pretreated with ISX1 in myocardial infarction (MI)-injured hearts leads to improved functional recovery. (A) Representative M-mode echocardiograms. (B) Ventricular systolic function depicted as percent fractional shortening (\%FS) in sham-operated mice, in hearts treated with cell diluent (phosphate-buffered saline, PBS), or in hearts transplanted with ADSCs treated with vehicle (DMSO) or ISX1. (C) Left ventricular end-diastolic dimension (LVEDD) in millimeters. (D) Left ventricular end-systolic dimension (LVESD) in millimeters. Data include $n=10$ in the sham-operated control group, $n=12$ in diluent of the cells-treated group, $n=15$ in (PBS), $n=15$ in the vehicle-treated ADSC-transplanted group, $n=13$ in the ISX1-treated ADSC-transplanted group. Data are presented as mean \pm SEM. ${ }^{*} p<0.05$, Sham versus diluent, vehicle-treated cells, ISX1-treated cells, ${ }^{* *} \mathrm{p}<0.05$, ISX1-treated cells versus diluent, vehicle-treated cells.

figure S6). This suggests that the long-term (3 weeks) improvement in cardiac function afforded by ISX1-primed ADSCs was not due to differences in initial infarct size.

To explore possible mechanisms whereby ISX1-treated ADSCs might improve cardiac function post-MI, we examined the extent of neovascularization in the MI-injured hearts. Isolectin B4 staining was used to mark endothelial cells lining blood vessels. Transplanted vehicle-treated ADSCs increased vessel density by approximately $20 \%$ over that of mock-transfected hearts (figure $7 \mathrm{~B}, \mathrm{C})(\mathrm{n}=7-11)$. This effect was doubled in hearts transplanted with ISX1-treated ADSCs with vessel densities increasing nearly $40 \%$ as compared with diluent-injected control hearts (figure $7 \mathrm{~B}, \mathrm{C}$ ). This suggests that enhanced vascularization contributes to the improvement in cardiac function in the ISX1-treatment arm.

Paracrine factors are believed to promote the protective effects of ADSCs on ischemic injury. To examine whether ISX treatment altered paracrine factor secretion by ADSCs, we performed an angiogenesis protein array on the cell culture medium from ADSCs treated with vehicle or ISX1. No dramatic differences were observed in the levels of paracrine factors tested between the two sample conditions. However, we did observe small differences in select cytokines and growth factors including an increase in granulocyte-colony stimulated factor (G-CSF) and 
A

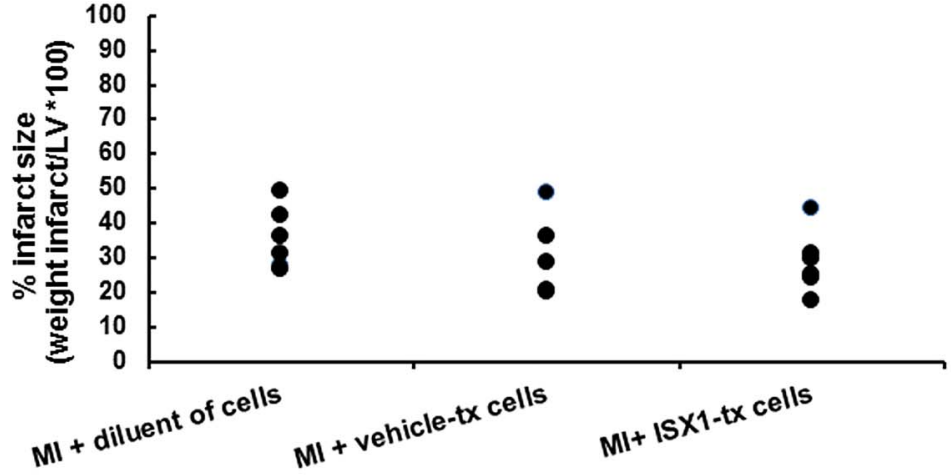

B FITC coniugated BS-IIsolectin B4

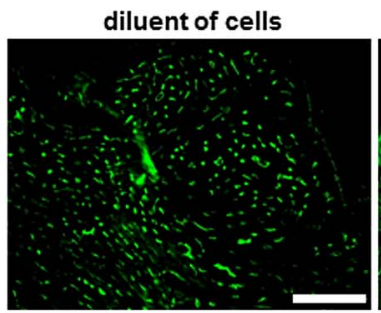

vehicle-tx cells
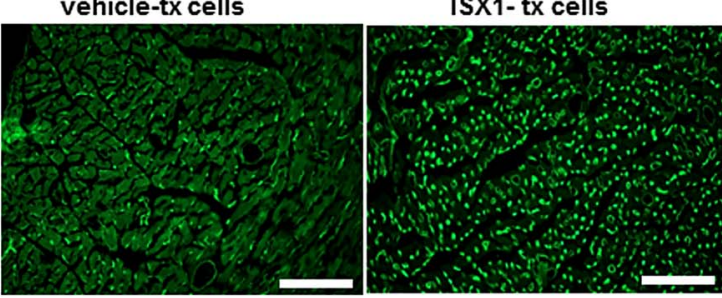

$*$

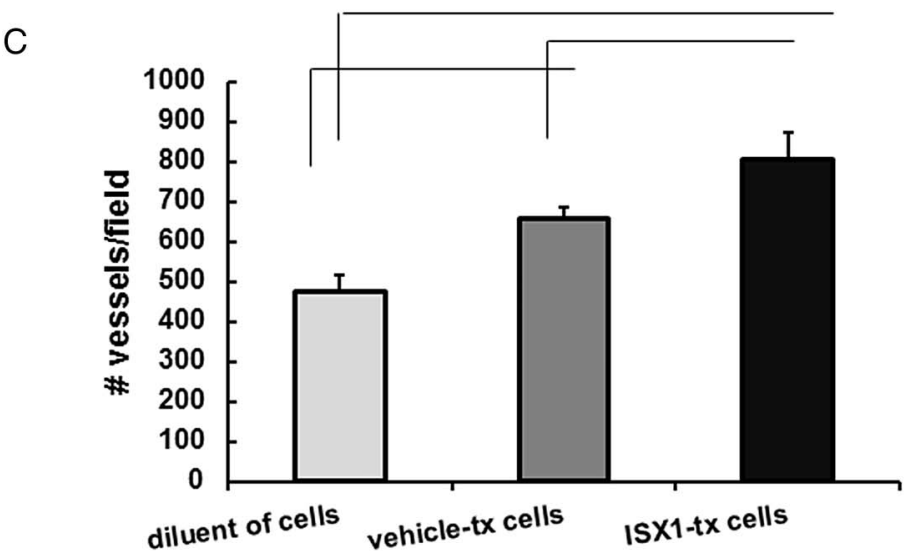

Figure 7 Enhanced neovascularization after adipose-derived stem cells (ADSC) transplantation but no difference in the original infarct size. (A) Percent infarct size between all groups (myocardial infarction (MI)+cell diluent (phosphate-buffered saline, PBS), MI+vehicle-treated cells, $\mathrm{MI}+\mathrm{ISX1}$-treated cells) as assessed by TTC (2,3,5-triphenyltetrazolium chloride) staining $(n=5-6)$. (B) Representative images of isolectin B4 staining (green) of blood vessels. Bar $=200 \mu \mathrm{m}$. (C) Quantification of vessel abundance normalized to microscopic field in hearts transplanted with ADSCs treated with cell diluent (PBS), vehicle (DMSO), or ISX1. Data are presented as mean \pm SEM; $(n=7-11) ;{ }^{*} p<0.05$.

interferon (IFN) $\gamma(\mathrm{n}=2)$ (see online supplementary figure S7). Thus, we believe it is unlikely that alterations in paracrine factor expression alone could account for the functional changes elicited when comparing hearts treated with the ISX1-treated ADSCs versus vehicle-treated ADSCs.

We next tested whether the transplanted cells persist in the infarcted myocardium, potentially acting more directly to improve cardiac function after MI. We isolated ADSCs from adipose tissue of mice that ubiquitously express GFP. At 3 weeks post-MI, no $\mathrm{GFP}^{+}$cells were detected in vehicletreated ADSC-transplanted hearts. In contrast, we detected $\mathrm{GFP}^{+}$cells in the ISX1-treated ADSC-transplanted hearts (see online supplementary figure S8, figure $8 \mathrm{~A}$ ). These $\mathrm{GFP}^{+}$ cells co-localized with troponin T-stained cardiac myocytes, suggesting that these cells manifest myocyte-like characteristics. Using confocal microscopy, we confirmed the presence of $\mathrm{GFP}^{+}$transplanted cells, and their co-localization to troponin T-stained cardiac myocytes (figure $8 \mathrm{~B}$ ). However, these transplanted cells did not appear to fully differentiate into cardiac myocytes.

An inventory of other tissues (approximately 15 histological sections each), including the kidney, lung, skeletal muscle, spleen, liver, and white adipose tissue, failed to reveal $\mathrm{GFP}^{+}$cells in either ISX1-treated or vehicle-treated ADSC transplanted hearts (see online supplementary figure S9), suggesting that cells transplanted into the myocardium did not home to other organs. Whereas no vehicle-treated ADSCs were detected at 3 weeks post-MI (figure 8A), increased neovascularization has been linked to paracrine factors released from these cells. ${ }^{44}$ However, the clear 
Table 1 Cell marker expression

\begin{tabular}{lcc}
\hline & SVF (\%) & P0 (\%) \\
\hline CD29 & 79 & 44 \\
CD34 & 52 & 17 \\
Sca1 & 60 & 38 \\
CD24 & 40 & 7 \\
CD105 & 30 & 17 \\
CD117 & 2 & 0 \\
CD44 & 0 & 2 \\
CD90 & 9 & 0 \\
CD73 & 36 & 7 \\
CD166 & 15 & 0 \\
CD31 & 2 & 0 \\
CD45 & 0 & 0 \\
CD11b & 14 & 1 \\
CD14 & 26 & 0 \\
Ter119 & 0 & 0 \\
\hline
\end{tabular}

Cell surface marker expression on freshly isolated stromal vascular fraction (SVF) and cells cultured for 4 days (PO). Both SVF and P0 cells expressed no endothelial cell or inflammatory cell markers but rather expressed markers of adipose progenitor cells, endothelial progenitor cells, and mesenchymal stem cells.

presence of ISX1-treated ADSCs at 3 weeks post-MI raises the prospect that paracrine actions elicited by these cells may be sustained and persistent relative to the more transient passage of vehicle-treated ADSCs. Together, these data suggest that the increase in neovascularization is due to localization of the ISX1-treated ADSCs to the myocardium, resulting in a more sustained paracrine-elicited effect.
Figure 8 Transplanted GFP ${ }^{+}$

adipose-derived stem cells (ADSCs)

pretreated with ISX1 detected in hearts

3 weeks postmyocardial infarction (MI)

and co-localized with cardiac

myocytes. (A) Representative images of

heart sections immunostained for

green fluorescent protein (GFP) (red)

and Troponin $\mathrm{T}$ (green). Bar $=40 \mu \mathrm{m}$.

(B) Confocal images of hearts

transplanted with ISX1-treated ADSCs.

GFP (red), Troponin T (green), overlap

(yellow). Bar=20 $\mu \mathrm{m}$.

\section{DISCUSSION}

Stem cell therapy for treatment of MI has been the subject of great hope and interest. However, the benefit afforded by this strategy is currently of modest impact, and therefore there is great interest in identifying means of enhancing it. Most evidence points to paracrine signaling events-which remain elusive-that promote repair.

We tested a strategy in which ADSCs, cells that are readily harvested from a rich and prevalent depot, are 'primed' by exposing them to ISX1, a small molecule previously established to promote stem cell differentiation toward a cardiomyocyte phenotype. ${ }^{22} 27$ We show that ISX1 treatment in culture promotes ADSC exit from the cell cycle and leads to expression of a variety of markers indicative of a cardiogenic lineage. Importantly, ISX suppressed differentiation into other cellular lineages. Mechanistically, ISX1 provoked increased HAT activity, an established mechanism governing stem cell differentiation and increased acetylation of specific histone residues. Finally, we observed that delivery of ISX1-primed ADSCs to the infarcted myocardium promoted rescue of the pathological remodeling phenotype above and beyond that afforded by vehicle-treated ADSCs. ISX1-treated ADSCs remained resident within the injured LV for up to 3 weeks, and their administration was associated with enhanced angiogenesis. Together, these findings point to a novel strategy that capitalizes on synergies between pharmacological and cell-based modalities. As a result, findings reported here raise the prospect that limitations which have plagued exogenous stem cell delivery to the injured myocardium may respond to pharmacological manipulation.
A

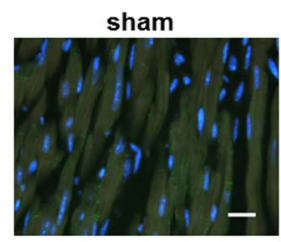

MI + diluent of cells
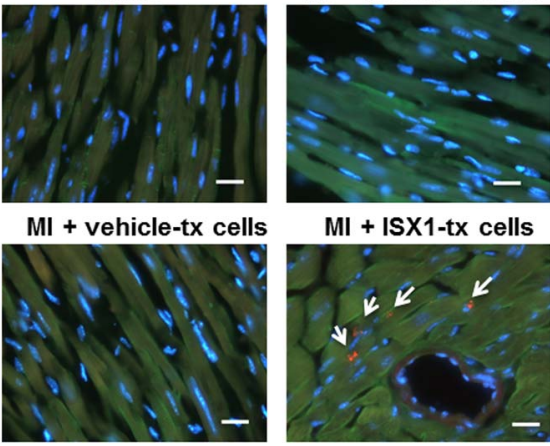

MI + ISX1-tx cells

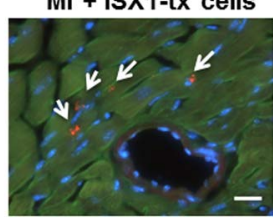

GFP (red) and Troponin T (green)

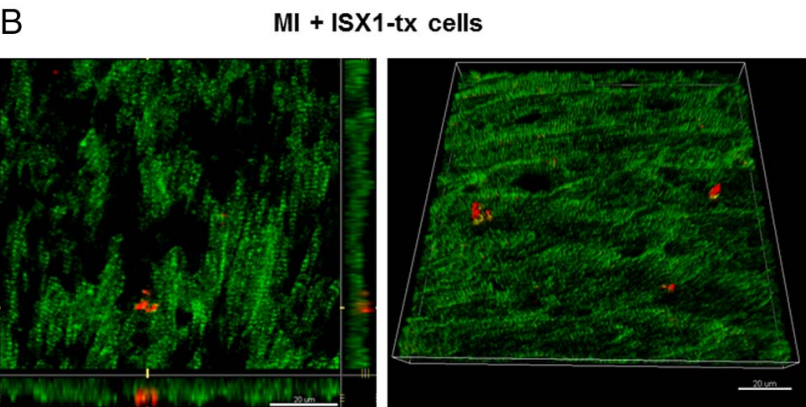

GFP (red), Troponin T (green), overlap (yellow) 
Table 2 PCR primers and antibodies used in analyses

\begin{tabular}{|c|c|}
\hline \multicolumn{2}{|c|}{$\begin{array}{l}\text { Real-time PCR TaqMan primers used in gene expression analyses. Antibodies and isotype control antibodies used to detect cell surface markers by flow } \\
\text { cytometry }\end{array}$} \\
\hline TaqMan Nkx2-5 primers & Mm00657783_m1 \\
\hline TaqMan Nppa primers (ANF) & Mm01255748_g1 \\
\hline TaqMan Nppb primers (BNP) & Mm 01255770_g1 \\
\hline TaqMan TnnC primers (Troponin C) & Mm00437111_m1 \\
\hline \multicolumn{2}{|c|}{ List of antibodies used for flow cytometry } \\
\hline Flow cytometry antibody & Isotype control \\
\hline PE anti-mouse CD29 & PE Armenian Hamster IgG \\
\hline eFluor660 CD34 & efluor660 rat lgG2a, $к$ \\
\hline PE-Cy7 anti-mouse Ly-6A/E (Sca1) & PE-Cy7 rat lgG2a, к \\
\hline PE anti-mouse CD24 & PE rat $\lg G 2 c, \kappa$ \\
\hline PE anti-mouse CD105 & PE rat $\lg G 2 a, \kappa$ \\
\hline PE-Cy7 anti-mouse CD117 (c-Kit) & PE-Cy7 rat lgG2a, к \\
\hline PE-Cy7 anti-mouse CD44 & PE-Cy7 rat lgG2b, к \\
\hline PE anti-mouse CD90.1 (Thy1.1) & PE mouse IgG2a, $\kappa$ \\
\hline PE anti-mouse CD73 & $\mathrm{PE}$ rat $\lg \mathrm{G} 1$ \\
\hline PE anti-mouse CD166 (ALCAM) & PE rat IgG2a, к \\
\hline PE-Cy7 anti-mouse CD31 & PE-Cy7 rat lgG2a, к \\
\hline PerCP-Cy5.5 anti-mouse CD45 & PerCP-Cy5.5 rat lgG2b, к \\
\hline PE-Cy7 anti-mouse CD11b & PE-Cy7 rat lgG2b, к \\
\hline PE anti-mouse CD14 & PE rat IgG2a, $\kappa$ \\
\hline PerCp-Cy5.5 anti-mouseTer119(Ly-76) & PerCP-Cy5.5 rat $\lg \mathrm{G} 2 \mathrm{~b}, \mathrm{\kappa}$ \\
\hline
\end{tabular}

\section{Myocardial regeneration using exogenously administered ADSCs}

We report that ADSCs improve cardiac function, a finding consistent with some previous reports. ${ }^{6-13}$ However, not all studies demonstrated improvements in LV functional recovery after ADSC or mesenchymal stem cell (MSC) transplantation. Failure to observe cardiac protection in some studies may be attributed to a relative lack of sensitivity of measures of ventricular function in large animals, such as porcine models. ${ }^{45}$ Assessment of regional myocardial function may provide a more sensitive metric of changes in myocardial function of modest magnitude.

The passage number of the cells used in transplants may also be critical for determining efficacy of treatment. Studies using ADSCs cultured for long periods of time and transplanted at passages $8-10$ demonstrated no benefit. ${ }^{46}$ Indeed, the protective effects of MSCs are lost between passages 5 and 10 , but retained until passage $3 .{ }^{47}$ Furthermore, in the setting of long-term culture (passage $>5$ ), chromosomal instability is observed in mouse ADSCs. ${ }^{48}$ Even in cells from adipose tissue selected for cardiomyocyte-like properties by culture on a semisolid methylcellulose medium, the cardiac phenotype was not efficiently maintained with extended time in culture. ${ }^{49}$

Another parameter that may determine whether ADSC transplantation is efficacious is timing of injection after infarction. Injecting cardiac pre-differentiated ADSCs at 1 month post MI was not associated with improvement in cardiac function, ${ }^{7}$ and these cells did not survive in a chronic infarction model. ${ }^{49}$ Even in an acute model, the number of transplanted mononuclear or mesenchymal cells declines with time after transplantation. ${ }^{50}$ Specifically, the percentage of donor cells retained in the heart decreased rapidly from $34-80 \%$ of injected cells $(0 \mathrm{~h})$ to $0-3.5 \%$ (6 weeks) independent of cell type, number, and application time. In our hands, we could not detect any vehicle-treated ADSCs retained in the heart 3 weeks post transplantation, whereas ISX1-treated ACSCs were still observed in the myocardium at this point, suggesting increased residence time of these transplanted cells. Importantly, a survey of other organs uncovered no transplanted cells, either ISX1-treated or untreated, at 3 weeks.

\section{Differentiation of ADSCs into cardiac progenitors}

We did not detect increased expression of late cardiac markers in ADSCs treated with ISX1 without co-culture with neonatal cardiac myocytes, nor did we observe full differentiation in vivo. This suggests that ISX1 alone is not sufficient to induce the full cardiac differentiation program, but rather promotes differentiation of cardiomyocyte progenitors. Alternatively, the heterogeneous population of cells we employed includes cell types that may harbor predefined epigenetic marks, which are unresponsive to ISX1, and therefore mask the effects of ISX1 in the responsive cell types. Additionally, it is possible that one or more cell types within such a heterogeneous population may inhibit the differentiation of other subpopulations. Pertinent to this, a novel population of multipotent stem cells from the SVF of adipose tissue has been identified as an early population of stem cells $\left(\mathrm{Lin}^{-}: \mathrm{CD} 29^{+}: \mathrm{CD} 34^{+}: \mathrm{Sca} 1^{+}: \mathrm{CD} 24^{+}\right)$ which can be induced to undergo adipogenesis, osteogenesis, and skeletal myogenesis. ${ }^{34} 51$ However, populations negative for CD34 or unfractionated SVF populations were incapable of forming myotubes when seeded with $\mathrm{C} 2 \mathrm{C} 12$ cells, suggesting the presence of cells within unfractionated SVF or $\mathrm{CD}^{-}$populations that repress myocyte 
differentiation. In accordance with this, we observed a trend toward enhanced responsiveness to ISX1 in subpopulations of cells expressing CD34 as measured by increased Troponin I expression (data not shown).

At the outset, we did not expect that a single cue could trigger full and complete cardiomyocyte differentiation, a process which is widely accepted to involve multiple steps. ${ }^{52}$ Also, the lack of full cardiac myocyte differentiation in our study could result from sustained expression of Nkx2-5. Although Nkx2-5 expression is necessary for heart development, cell differentiation involves a dynamic process whereby genes are expressed early in differentiation and subsequently repressed. The precise timing of expression may be necessary for correct and full differentiation. In addition, the point at which a stem cell is positioned along a progression of differentiation may also determine which transcription factors are necessary for re-programming. Indeed, a recent study reported that elimination of $\mathrm{Nkx} 2-5$ in a transcription factor cocktail augmented re-programming of adult fibroblasts, ${ }^{53}$ suggesting that (1) Nkx2-5 was unable to induce transcription of the myosin heavy chain promoter or (2) adult cells employ transcription factors other than those used by embryonic stem cells in heart development. Whether activation of other transcription factors in ADSCs is more efficacious to induce their differentiation into cardiac myocytes is not known.

\section{Mechanisms of repair}

Although we did observe retention of cells in the ISX1 treatment arms at 3 weeks post-MI, their small numbers and incomplete differentiation suggest that the functional benefits to the heart are unlikely due to engraftment of functional myocytes. This was expected. Rather, our findings suggest that transplanted stem cells pre-differentiated pharmacologically are better able to trigger events in the neighboring tissue that promote the healing process.

In fact, previous studies have shown that ADSCs improve cardiac function by increasing both capillary and arteriole densities despite low absolute rates of engraftment. ${ }^{8} 54$ Consistent with this, we found increased neovascularization in response to transplantation of ADSCs, which was augmented by ISX1. It is possible that this increase in neovascularization is due to the localization of ISX1-treated ADSCs to the myocardium resulting in a more sustained paracrine-elicited effect.

\section{Chromatin remodeling}

Chromatin remodeling involves changes in the methylation state of DNA and post-translational modifications of histone proteins that regulate chromatin conformation. DNA methylation of a gene promoter typically leads to transcriptional silencing. However, a recent report suggests that there is no correlation between DNA methylation state and gene expression in ADSCs. ${ }^{55}$ Specifically, ADSCs can differentiate toward myogenic and endothelial lineages despite hypermethylation of the non-adipogenic lineagespecific promoters MYOG and CD31. ${ }^{55}$ In addition, during P19CL6 differentiation into cardiac myocytes, the DNA methylation status at the Nkx2-5 promoter did not change, suggesting that DNA methylation does not play a major role in ADSC-induced cardiomyogenesis in our study. ${ }^{56}$ However, many studies have shown that treatment of
ADSCs with the DNA methylation inhibitor, 5-azacytidine, promotes cardiomyogenesis. ${ }^{57}$ This may be due to the effects of 5 -azacytidine on histone modifications. ${ }^{37}$

Histone methylation and acetylation states are major determinants of chromatin structure and transcriptional activity, including the transcriptional processes of stem cell differentiation. We did not observe an ISX1-elicited decrease in trimethylated histone 3 lysine 9 (H3K9me3), which is enriched in heterochromatin, ${ }^{58}$ nor an increase in the active mark trimethylated histone 3 lysine 4 (H3K4me3), suggesting that histone methylation may not be a major underlying mechanism.

Alternatively, histones can be acetylated and deacetylated by HATs and HDACs, respectively. We did not observe a difference in HDAC activity in the nuclei of ADSCs exposed to ISX1 or vehicle. Further, we observed no additive or synergistic effects using HDAC inhibitors. However, we did observe an increase in HAT activity in response to ISX1. Congruent with this, we observed an increase in global histone acetylation. Specifically, we detected an increase in the acetylation of histone 4 lysine 8 (H4K8) and histone 3 lysine 9 (H3K9). H4K8 acetylation occurs in neonatal cardiomyocytes in response to 5 -azacytidine ${ }^{37}$ and may be important in cardiac myocyte differentiation. In addition, our findings that ISX1 decreased osteogenesis and increased $\mathrm{H} 3 \mathrm{~K} 9$ acetylation are in alignment with a decrease in global $\mathrm{H} 3 \mathrm{~K} 9$ acetylation in MSC-induced osteogenic differentiation. ${ }^{38}$

\section{Summary and perspective}

Cell-based strategies of myocardial repair hold considerable promise in ischemic heart disease, heart failure, and other cardiovascular pathologies. However, efficacy in preclinical and clinical trials remains modest, highlighting the need to identify novel means of enhancing the treatment effect. The findings reported here suggest that an approach which couples thoughtful selection of multipotent cells receptive to exogenous differentiation cues along with novel triggers of differentiation holds promise in the development and exploitation of this important treatment strategy.

Funding This work was supported by grants from the NIH (HL-120732; HL100401), American Heart Association (14SFRN20740000), CPRIT (RP110486P3), and the Leducq Foundation (11CVD04).

Competing interests None declared.

Provenance and peer review Not commissioned; externally peer reviewed.

Data sharing statement We are committed to sharing any unique resources reported in this paper. Additional, unpublished data is available to collaborators or other investigators upon written request. Should any intellectual property arise, which requires a patent, we would ensure that the technology remains widely available to the research community in accordance with NIH Principles and Guidelines.

\section{REFERENCES}

1 Burchfield JS, Xie M, Hill JA. Pathological ventricular remodeling: mechanisms: part 1 of 2. Circulation 2013;128:388-400.

2 Xie M, Burchfield JS, Hill JA. Pathological ventricular remodeling: therapies: part 2 of 2. Circulation 2013;128:1021-30.

3 Abdel-Latif A, Bolli R, Tleyjeh IM, et al. Adult bone marrow-derived cells for cardiac repair: a systematic review and meta-analysis. Arch Intern Med 2007;167:989-97.

4 Lipinski MJ, Biondi-Zoccai GG, Abbate A, et al. Impact of intracoronary cell therapy on left ventricular function in the setting of acute myocardial infarction: a collaborative systematic review and meta-analysis of controlled clinical trials. J Am Coll Cardiol 2007;50:1761-7. 
5 Strem BM, Hicok KC, Zhu M, et al. Multipotential differentiation of adipose tissue-derived stem cells. Keio J Med 2005;54:132-41.

6 Cai L, Johnstone BH, Cook TG, et al. IFATS collection: human adipose tissue-derived stem cells induce angiogenesis and nerve sprouting following myocardial infarction, in conjunction with potent preservation of cardiac function. Stem Cells 2009;27:230-7.

7 Mazo M, Planat-Benard V, Abizanda G, et al. Transplantation of adipose derived stromal cells is associated with functional improvement in a rat model of chronic myocardial infarction. Eur J Heart Fail 2008;10:454-62.

8 Schenke-Layland K, Strem BM, Jordan MC, et al. Adipose tissue-derived cells improve cardiac function following myocardial infarction. J Surg Res 2009;153:217-23

9 Valina C, Pinkernell K, Song YH, et al. Intracoronary administration of autologous adipose tissue-derived stem cells improves left ventricular function, perfusion, and remodelling after acute myocardial infarction. Eur Heart J 2007;28:2667-77

10 Yamada Y, Wang XD, Yokoyama S, et al. Cardiac progenitor cells in brown adipose tissue repaired damaged myocardium. Biochem Biophys Res Commun 2006;342:662-70.

11 Zhang DZ, Gai LY, Liu HW, et al. Transplantation of autologous adipose-derived stem cells ameliorates cardiac function in rabbits with myocardial infarction. Chin Med J (Engl) 2007;120:300-7.

12 Hwangbo S, Kim J, Her S, et al. Therapeutic potential of human adipose stem cells in a rat myocardial infarction model. Yonsei Med J 2010;51:69-76.

13 Wang L, Deng J, Tian W, et al. Adipose-derived stem cells are an effective cell candidate for treatment of heart failure: an MR imaging study of rat hearts. Am J Physiol Heart Circ Physiol 2009;297:H1020-31.

14 Penn MS. Cell-based gene therapy for the prevention and treatment of cardiac dysfunction. Nat Clin Pract Cardiovasc Med 2007;4(Suppl 1):S83-8.

15 Penn MS, Khalil MK. Exploitation of stem cell homing for gene delivery. Expert Opin Biol Ther 2008:8:17-30.

16 Penn MS, Mangi AA. Genetic enhancement of stem cell engraftment, survival, and efficacy. Circ Res 2008;102:1471-82.

17 Laflamme MA, Chen KY, Naumova AV, et al. Cardiomyocytes derived from human embryonic stem cells in pro-survival factors enhance function of infarcted rat hearts. Nat Biotechnol 2007;25:1015-24.

18 Grauss RW, van Tuyn J, Steendijk P, et al. Forced myocardin expression enhances the therapeutic effect of human mesenchymal stem cells after transplantation in ischemic mouse hearts. Stem Cells 2008;26:1083-93.

19 Hahn JY, Cho HJ, Kang HJ, et al. Pre-treatment of mesenchymal stem cells with a combination of growth factors enhances gap junction formation, cytoprotective effect on cardiomyocytes, and therapeutic efficacy for myocardial infarction. J Am Coll Cardiol 2008:51:933-43.

20 Ivey $\mathrm{KN}$, Muth $\mathrm{A}$, Arnold J, et al. MicroRNA regulation of cell lineages in mouse and human embryonic stem cells. Cell Stem Cell 2008:2:219-29.

21 Bian J, Popovic ZB, Benejam C, et al. Effect of cell-based intercellular delivery of transcription factor GATA4 on ischemic cardiomyopathy. Circ Res 2007; 100:1626-33.

22 Sadek H, Hannack B, Choe E, et al. Cardiogenic small molecules that enhance myocardial repair by stem cells. Proc Natl Acad Sci USA 2008; 105:6063-8

23 Garry DJ, Olson EN. A common progenitor at the heart of development. Cell 2006;127:1101-4.

24 Schneider JW, Gao Z, Li S, et al. Small-molecule activation of neuronal cell fate. Nat Chem Biol 2008;4:408-10.

25 Takahashi T, Lord B, Schulze PC, et al. Ascorbic acid enhances differentiation of embryonic stem cells into cardiac myocytes. Circulation 2003;107:1912-16.

26 Wu X, Ding S, Ding Q, et al. Small molecules that induce cardiomyogenesis in embryonic stem cells. J Am Chem Soc 2004;126:1590-1.

27 Russell JL, Goetsch SC, Aguilar HR, et al. Targeting native adult heart progenitors with cardiogenic small molecules. ACS Chem Biol 2012;7:1067-76.

28 Zhang L, Li P, Hsu T, et al. Small-molecule blocks malignant astrocyte proliferation and induces neuronal gene expression. Differentiation 2011;81:233-42.

29 Velasquez LS, Sutherland LB, Liu Z, et al. Activation of MRTF-A-dependent gene expression with a small molecule promotes myofibroblast differentiation and wound healing. Proc Natl Acad Sci USA 2013; 110:16850-5.

30 Dioum EM, Osborne JK, Goetsch S, et al. A small molecule differentiation inducer increases insulin production by pancreatic beta cells. Proc Natl Acad Sci USA 2011;108:20713-18.
31 Ni YG, Wang N, Cao DJ, et al. FoxO transcription factors activate Akt and attenuate insulin signaling in heart by inhibiting protein phosphatases. Proc Natl Acad Sci USA 2007:104:20517-22.

32 Xie $M$, Kong $Y$, Tan W, et al. Histone deacetylase inhibition blunts ischemia/ reperfusion injury by inducing cardiomyocyte autophagy. Circulation 2014;129:1139-51.

33 Furness SG, McNagny K. Beyond mere markers: functions for CD34 family of sialomucins in hematopoiesis. Immunol Res 2006;34:13-32.

34 Rodeheffer MS, Birsoy K, Friedman JM. Identification of white adipocyte progenitor cells in vivo. Cell 2008;135:240-9.

35 Suga $H$, Matsumoto $D$, Eto $H$, et al. Functional implications of CD34 expression in human adipose-derived stem/progenitor cells. Stem Cells Dev 2009;18:1201-10.

36 Cheung WL, Briggs SD, Allis CD. Acetylation and chromosomal functions Curr Opin Cell Biol 2000;12:326-33.

37 Kou CY, Lau SL, Au KW, et al. Epigenetic regulation of neonatal cardiomyocytes differentiation. Biochem Biophys Res Commun 2010;400:278-83.

38 Tan J, Lu J, Huang W, et al. Genome-wide analysis of histone H3 lysine9 modifications in human mesenchymal stem cell osteogenic differentiation. PLOS ONE 2009:4:e6792.

39 Struhl K. Histone acetylation and transcriptional regulatory mechanisms. Genes Dev 1998;12:599-606.

40 Fuks F. DNA methylation and histone modifications: teaming up to silence genes. Curr Opin Genet Dev 2005;15:490-5.

41 Schneider R, Bannister AJ, Myers FA, et al. Histone H3 lysine 4 methylation patterns in higher eukaryotic genes. Nat Cell Biol 2004;6:73-7.

42 Bernstein BE, Kamal M, Lindblad-Toh $\mathrm{K}$, et al. Genomic maps and comparative analysis of histone modifications in human and mouse. Cell 2005;120:169-81.

43 Lin CS, Xin ZC, Deng CH, et al. Defining adipose tissue-derived stem cells in tissue and in culture. Histol Histopathol 2010;25:807-15.

44 Burchfield JS, Dimmeler S. Role of paracrine factors in stem and progenitor cell mediated cardiac repair and tissue fibrosis. Fibrogenesis Tissue Repair 2008;1:4.

45 Rigol M, Solanes N, Farre J, et al. Effects of adipose tissue-derived stem cell therapy after myocardial infarction: impact of the route of administration. $J$ Card Fail 2010;16:357-66.

46 van der Bogt KE, Schrepfer S, Yu J, et al. Comparison of transplantation of adipose tissue- and bone marrow-derived mesenchymal stem cells in the infarcted heart. Transplantation 2009;87:642-52.

47 Crisostomo PR, Wang M, Wairiuko GM, et al. High passage number of stem cells adversely affects stem cell activation and myocardial protection. Shock 2006;26:575-80.

48 Qin $Y$, Ji H, Wu Y, et al. Chromosomal instability of murine adipose tissue-derived mesenchymal stem cells in long-term culture and development of cloned embryos. Cloning Stem Cells 2009:11:445-52.

49 Leobon B, Roncalli J, Joffre C, et al. Adipose-derived cardiomyogenic cells: in vitro expansion and functional improvement in a mouse model of myocardial infarction. Cardiovasc Res 2009;83:757-67.

50 Muller-Ehmsen J, Krausgrill B, Burst V, et al. Effective engraftment but poor mid-term persistence of mononuclear and mesenchymal bone marrow cells in acute and chronic rat myocardial infarction. J Mol Cell Cardiol 2006:41:876-84

51 Tang $W$, Zeve $D$, Suh JM, et al. White fat progenitor cells reside in the adipose vasculature. Science 2008;322:583-6

52 Keller G. Embryonic stem cell differentiation: emergence of a new era in biology and medicine. Genes Dev 2005;19:1129-55.

53 Song K, Nam YJ, Luo X, et al. Heart repair by reprogramming non-myocytes with cardiac transcription factors. Nature 2012;485:599-604.

54 Li B, Zeng Q, Wang $H$, et al. Adipose tissue stromal cells transplantation in rats of acute myocardial infarction. Coron Artery Dis 2007;18:221-7.

55 Noer A, Sorensen AL, Boquest AC, et al. Stable CpG hypomethylation of adipogenic promoters in freshly isolated, cultured, and differentiated mesenchymal stem cells from adipose tissue. Mol Biol Cell 2006;17:3543-56.

56 Liu Z, Li T, Liu Y, et al. WNT signaling promotes Nkx2.5 expression and early cardiomyogenesis via downregulation of Hdac1. Biochim Biophys Acta 2009:1793:300-11

57 Choi YS, Dusting GJ, Stubbs S, et al. Differentiation of human adipose-derived stem cells into beating cardiomyocytes. I Cell Mol Med 2010;14:878-89.

58 Barski A, Cuddapah S, Cui K, et al. High-resolution profiling of histone methylations in the human genome. Cell 2007:129:823-37. 